\title{
Distributed Generation Stability During Fault Conditions
}

\author{
A. S. El Safty ${ }^{1}$, B. M. Abd El Geliel ${ }^{1}$ and C. M. Ammar ${ }^{1}$ \\ ${ }^{1}$ Department of Electrical Power\& Control Engineering \\ College of Engineering \& Technology \\ Arab Academy for Science, Technology \& Maritime Transport (Egypt) \\ Phone/Fax number:+002035614956, e-mail: drsamahsafty@yahoo.com, malgeliel@yahoo.com
}

\begin{abstract}
The difficulties facing electric utility companies to satisfy on-site customer power demand aroused an increasing interest in small distributed generators (DG). Also the environmental concerns, the technology evolution and the need to integrate renewable energy resources into distribution system gave way to the construction of (DG) using alternative energy sources. The presence of such new generators creates new operating conditions for the interconnected system. The aim of the paper is to study the impacts of faults on stability in systems with (DG) and their satiability during faults. In this paper, the impact of different types of faults at various locations on a distribution system with and without the presence of (DG) is studied. The IEEE 13 node distribution test feeder is used as a model for the study together with synchronous generator (DG). The simulation of the distribution system and the (DG) is performed using PSCAD software. A comparison between fault currents with and without the insertion of the DG is carried. The effect of such faults on the stability of the used DG is considered taking into account the control actions expected for the system to remain within the stability limit. A tuned PID controller is used to enhance the DG transients due to different load changes and faults. The results of simulation are discussed and the scope of the future work is highlighted.
\end{abstract}

\section{Key words}

Distributed generator, Distribution system, fault analysis, IEEE node test feeder, synchronous generator. 